\title{
Population-based study of medically treated self-inflicted injuries
}

\author{
Ian Colman, MSc; ${ }^{*}$ Niko Yiannakoulias, MA $;^{\dagger}$ Don Schopflocher, PhD $;^{\dagger}$ Lawrence W. Svenson, BSc; ${ }^{\dagger}$ \\ Rhonda J. Rosychuk, PhD; $;$ Brian H. Rowe, MD, MSc $;$ for the ED Atlas Group ${ }^{\mathbb{I}}$
}

\begin{abstract}
Objective: Self-inflicted injury is commonly seen in emergency departments (EDs). It may be a precursor to death by suicide. The objective of this study was to examine the epidemiology of self-inflicted injury presentations to EDs in the province of Alberta.

Methods: Self-inflicted injury records for the 3 fiscal years 1998/99 to 2000/01 were accessed from the Ambulatory Care Classification System, a database that captures all ED encounters in the province of Alberta. Available data for each case included demographic details, location and time of visit, diagnoses and procedures.

Results: There were 22396 self-inflicted injury presentations to Alberta EDs during the study period. Self-inflicted injury rates were higher in females, younger patients, those on social services and those with Aboriginal treaty status. There were higher rates of return visits in the year following the self-inflicted injury than in other patient groups. Data showed regional variation. Trends could be seen in the timing of self-inflicted injury presentations by hour of day, day of week, and month of year.

Conclusions: Self-inflicted injury is common, with particularly high rates demonstrated among marginalized populations. This study provides comprehensive data on those who present with self-inflicted injuries, and can be used to guide further treatment, research and evaluation for this population.
\end{abstract}

Key words: self-injurious behaviour; attempted suicide; prevalence; epidemiology

\begin{abstract}
RÉSUMÉ
Objectif : On rencontre souvent des cas de blessures volontaires au département d'urgence (DU). Celles-ci peuvent être un précurseur d'une mort par suicide. La présente étude avait comme objectif d'examiner l'épidémiologie des cas de blessures volontaires dans les DU de la province de l'Alberta. Méthodes : Les dossiers de blessures volontaires pour les trois années financières de 1998/1999 à 2000/2001 furent obtenus du Ambulatoray Care Classification System (Système de classification des soins ambulatoires), une banque de données qui enregistre toutes les visites au DU dans la province de l'Alberta. Les données disponibles pour chaque cas comprenaient les détails démographiques, le lieu et l'heure de la visite, le diagnostic et les interventions.
\end{abstract}

\footnotetext{
*Department of Psychiatry, University of Cambridge, Cambridge, United Kingdom †Alberta Health and Wellness, Edmonton, Alta.

¥Department of Pediatrics, University of Alberta, Edmonton, Alta.

§Division of Emergency Medicine, University of Alberta, Edmonton, Alta.

Inee screened box at end of the article for list of the other members of the ED Atlas Group.
}

Received: Mar. 3, 2004; final submission: June 20, 2004; accepted: June 23, 2004

This article has been peer reviewed.

Can J Emerg Med 2004;6(5):313-20 
Résultats : Il y eut 22396 cas de blessures volontaires dans les DU de l'Alberta au cours de la période à l'étude. Les taux de blessures volontaires étaient plus élevés parmi les femmes, les patients plus jeunes, ceux vivant de l'aide sociale et ceux détenant un statut autochtone issu de traités. Les taux de visites de retour pendant l'année suivant la blessure volontaire étaient plus élevés que ceux de d'autres groupes de patients. Les données indiquaient des variations régionales. On remarquait des tendances quant au moment de présentation des blessures volontaires selon I'heure du jour, le jour de la semaine et le mois de l'année.

Conclusions : Les blessures volontaires sont courantes, avec des taux particulièrement élevés au sein des populations marginalisées. La présente étude offre des données exhaustives au sujet des personnes reçues pour des blessures volontaires et pourrait servir à l'orientation du traitement, de la recherche et de l'évaluation de cette population.

\section{Introduction}

Self-inflicted injuries represent a serious public health issue. A recent international review found that $3 \%-5 \%$ of individuals respond "Yes" to the question "Have you ever attempted suicide?" Self-inflicted injuries are commonly referred to as "suicide attempts," presuming suicidal intent for all such acts. This is not always the case. In this paper we use the term "self-inflicted injury," based on the clinical modification of the International Classification of Diseases, 9th revision (ICD-9-CM) heading, which also includes "self-inflicted poisoning."

Individuals who deliberately injure themselves suffer from a wide variety of problems. Rates of psychiatric disorders, substance abuse, family and intimate partner violence, chronic illness and poor physical health, and unemployment/financial difficulties are higher than in the general population. ${ }^{3-7}$ In addition, this group has increased mortality rates not only from suicide but also from violence, injuries, and natural causes such as circulatory and respiratory system disorders..$^{8-11}$

Individuals who self-inflict injuries are predisposed to future self-harming and suicidal behaviour. Within 1 year of the index self-injury, $16 \%$ will repeat a similar act. ${ }^{12}$ Seven percent of individuals who harm themselves will eventually die of suicide, a rate 42 times higher than that of the general population. ${ }^{9}$ The variety of problems and severity of outcomes associated with self-inflicted injuries underscore their importance as a public health issue. Accurate and population-based data are necessary to direct research and programs for the self-harming population.

Large-scale studies have attempted to describe the prevalence and characteristics of self-harming behaviour. The World Health Organization/EURO Multicentre Project on Parasuicide (WHO/EURO) collected data on self-inflicted injuries from selected health care institutions in 16 European urban centres. ${ }^{13}$ The National Institute of Mental Health Epidemiologic Catchment Area Study collected data on self-reported suicide attempts in 5 US urban centres. ${ }^{14}$ Finally, a recent study collected data on hospitalizations for self-inflicted injuries in 8 states in the US, including some data on emergency visits. ${ }^{15}$ Although these studies have provided information regarding self-harming behaviour, none have been all-inclusive for a geographically defined population. Furthermore, such data have not been reported to date for a Canadian population.

The objective of this study was to use such a provincial administrative database to describe the prevalence of selfinflicted injuries and characteristics associated with the act in a population of over 3 million individuals.

\section{Methods}

\section{Data source}

The data for this study were obtained from the Ambulatory Care Classification System (ACCS), a database that tracks, among other information, all emergency department (ED) services provided in the province of Alberta. Since the Canadian health care system is a public, single payer system, the ACCS database captures almost every medical event resulting in emergency treatment.

Each record in ACCS contains a personal health number (unique to each person residing in the province), the service provided, the date and time of visit, diagnoses and disposition status. The personal health number is used to link health records to demographic data through the Alberta Health Care Insurance Stakeholder Registry (which includes over $99 \%$ of the population). The registry includes data on age, gender, region of residence and health care premium subsidy level (see below).

\section{Variables presented}

Diagnoses: Trained medical records nosologists code each ED encounter in each hospital according to the ICD-9-CM codes prior to electronic submission to Alberta Health and Wellness. The ACCS database contains up to 6 diagnoses 
and 4 additional injury fields for each record. Any record that contained a code of E950-E959 in one of the injury fields (either "Suicide and Self-inflicted poisoning" or "Suicide and Self-inflicted injury") was identified as a selfinflicted injury and included in this study. The diagnostic fields were also used to identify the method used in the self-inflicted injury: any code from E950.0-E950.9 was considered a "Self-poisoning," any code of E956 was considered a "Cutting or piercing," any code from E951.0-E953.9, E955.0-E955.9 or E957.0-E957.9 was considered a "Firearms/hanging/jumping/gas," and any code of E954 or E958.0-E959 was considered an "Other."

Date and time: The month of year and day of week are coded according to when the emergency service was accessed. Time of visit is reduced to hour of visit (e.g., a visit at $1143 \mathrm{~h}$ is coded as $1100 \mathrm{~h}$ ) and reflects the time of presentation to the ED (usually triage time).

Disposition: The disposition describes the manner in which an individual is separated/released from the emergency service facility. Disposition includes 4 categories: discharged, admitted in the same facility, transferred to another facility, and left (without being seen or against medical advice).

Age: The age from the registry database is the age of the individual at the end of the fiscal year. Age is grouped into 5-year intervals.

Gender: All individuals in the registry database are coded as male or female gender.

Region of residence: In this database, the province of Alberta was divided into 17 health regions. The region of residence is reported according to where the individual lived at the end of the fiscal year, not where the service was received.

Subsidy level: Health care in Alberta is funded by the government and financed in part through health care insurance premiums. Residents with lower incomes or receiving social services (e.g., welfare) are eligible for subsidies for these health premiums. The subsidy level can therefore be used as a proxy measure for socio-economic status. In addition, many Aboriginal individuals in Alberta have "Treaty" status based on treaties between their First Nation bands and the federal government. These treaties entitle comprehensive health care for any member of the First Nation band that signed the treaty. (For further definition of "Treaty" status, please see reference to Indian and Northern Affairs Canada.$^{16}$ ) Consequently, the subsidy level variable is divided into 4 groups: "No subsidy" — higher income individuals, "Full/Partial subsidy" - lower income individuals, "Social services" - recipients of welfare programs, and "Treaty status" - Aboriginal people with treaty status.

\section{Data analysis}

Data analysis for this study is descriptive only. Numbers of visits classified by the above variables are presented, along with percentages. All rates presented are "person-based" and are calculated by dividing the number of unique individuals who had at least one self-inflicted injury visit by the mid-year Alberta population for that year. Each table and graph identifies whether visits (which include repeat visits by the same person) or rates (which are person-based and do not include repeat visits by the same person) are being presented. On each graph a locally weighted polynomial regression function was used to help visualize the relative differences in frequencies and age-specific rates. ${ }^{17}$ The smoothing function parameter (i.e., LOWESS) is reported on each graph and indicates the proportion of observations used to smooth each data point.

These data were extracted for 3 fiscal years, comprising the period from Apr. 1, 1998, to Mar. 31, 2001. The protocol for this study was approved by the Health Research Ethics Board of the University of Alberta.

\section{Results}

The catchment population of this study was the slightly more than 3 million residents of the province of Alberta (Table 1). In the first year of the study (1998/1999), 104 emergency care facilities reported to the ACCS database. One hundred and two facilities reported in 1999/2000, and 103 in 2000/2001. There were 4887512 ED visits cap-

\begin{tabular}{|c|c|c|c|c|c|}
\hline \multirow[b]{2}{*}{ Fiscal year } & \multirow[b]{2}{*}{$\begin{array}{l}\text { Total no. } \\
\text { of ED visits }\end{array}$} & \multicolumn{2}{|c|}{ Self-inflicted injury visits } & \multirow[b]{2}{*}{$\begin{array}{c}\text { Alberta } \\
\text { population }\end{array}$} & \multirow{2}{*}{$\begin{array}{l}\text { Person-based } \\
\text { self-inflicted injury } \\
\text { crude rate per } \\
100000 \text { persons }\end{array}$} \\
\hline & & $\begin{array}{l}\text { Total no. of visits } \\
\text { (and \% of total } \\
\text { ED visits) }\end{array}$ & $\begin{array}{l}\text { No. of } \\
\text { unique } \\
\text { visits }\end{array}$ & & \\
\hline 1998/1999 & 1550135 & $7082(0.46)$ & 5666 & 3001877 & 188.7 \\
\hline $1999 / 2000$ & 1638652 & $7552(0.46)$ & 5902 & 3048335 & 193.6 \\
\hline $2000 / 2001$ & 1698725 & $7762(0.46)$ & 6112 & 3099627 & 197.2 \\
\hline
\end{tabular}


tured in this data set, of which 22396 were coded as selfinflicted injuries. There was a small increase in the absolute number of self-inflicted injury visits over the 3-year study period (Table 1 ).

Age and gender showed consistent trends in self-inflicted injury behaviour over the 3-year period (see Fig. 1 for 2000/2001 rates). In the 15- to 19-year age group, the rate for females was more than twice as high as those for males. The rates for females remained higher until approximately age 65 , beyond which males had slightly higher rates.

Notable differences were observed in the data with regard to timing of self-inflicted injury presentations (Fig. 2, Fig. 3 and Fig. 4). Patients under 20 years of age (children) presented less frequently for self-inflicted injury than those age 20 and over (adults). Lowest rates for self-injury in adults were seen from November to February, and for children it was during the middle of summer. Adults were most likely to present on Saturdays or Sundays, and for children it was Sundays or Mondays. Adults' visits peaked in late morning (1000h-1159h), but were also high in the evening (2000h-2359h). For children, there was a smaller rise in the number of visits in the late morning, with rates peaking at night (2100h-0159h) (Fig. 5).

Self-inflicted injury rates appear to vary with socio-economic status (Table 2). Individuals receiving social services had rates at least 10 times higher than those who received no subsidy. Those with "Treaty" status were also at greater risk, with rates at least 7 times higher than those who received no subsidy.

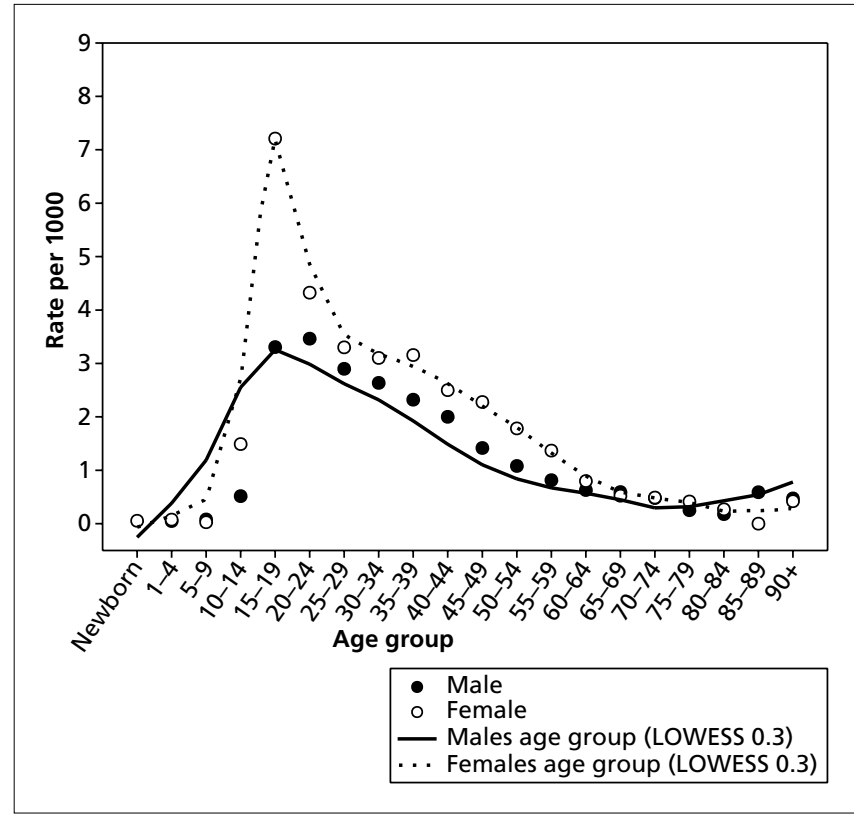

Fig. 1. Self-inflicted injury rates by age and gender, 2000/2001
Methods used to self-inflict injury varied according to gender (Table 3). Although overdoses accounted for the majority of self-inflicted injuries for both, males were more likely to use more lethal methods, such as firearms, hanging, jumping or poisoning by gas. Males were also more likely to use "Other" methods (E958), which included extremes of heat or cold, electrocution and suicidal behaviour involving a moving object or vehicle.

Overall, $64 \%$ of individuals presenting with a self-inflicted injury were discharged from the ED (Table 4). Individuals who cut/pierced themselves were most likely to be discharged, and those who used the more lethal methods mentioned above were most likely to be admitted or transferred to another facility. From 18\%-19\% re-injured themselves within a year, with approximately two-thirds of all individuals returning for varied problems to the ED in the following 365 days.

Finally, there was considerable variation in self-inflicted injury rates regionally through the province. Most notably, rates in the city of Edmonton were markedly higher than rates in the city of Calgary for all 3 years (data not shown).

\section{Discussion}

This province-wide, 3-year study of ED visits for self-inflicted injuries identifies that self-inflicted injuries are common and need to be recognized as a public health priority. The crude rate (person-based) reported of approximately 190 per 100000 per year is comparable to the rates reported from the 16 centres of the WHO/EURO study ${ }^{18}$

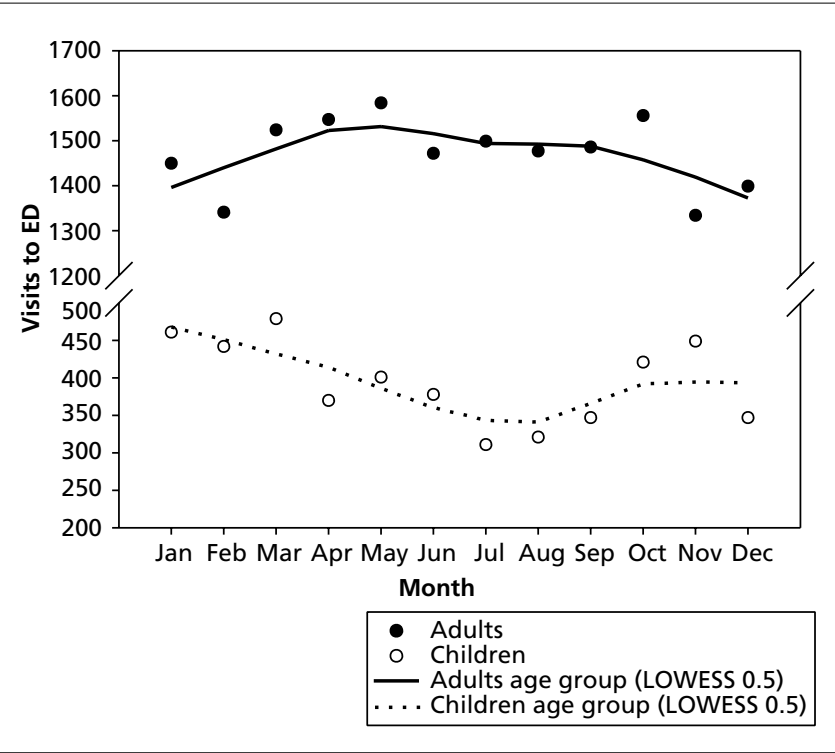

Fig. 2. Self-inflicted injury visits by month of year, 1998 to 2001 
and to the rates (visit-based) reported from 8 US states. ${ }^{15}$ Using comprehensive and non-biased data, this study was also able to show that many socio-demographic trends in Alberta are similar to those reported in other countries. Rates are higher among females, particularly in the 15- to 24-year age group. ${ }^{13-15,19}$ Rates are also higher among those in lower socio-economic brackets, particularly among those who require social service assistance. ${ }^{13,14,19}$ Finally, rates of suicidal behaviour are significantly higher among members of the Aboriginal community. ${ }^{20-24}$ It may be important to pay particularly close attention to these segments of the population in future research and programmatic planning.

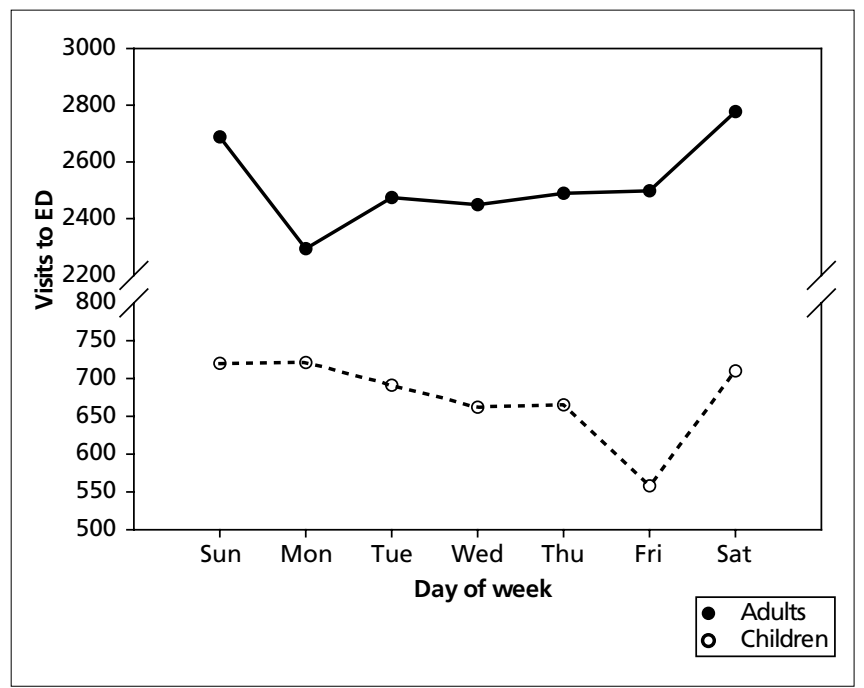

Fig. 3. Self-inflicted injury visits by day of week, 1998 to 2001.

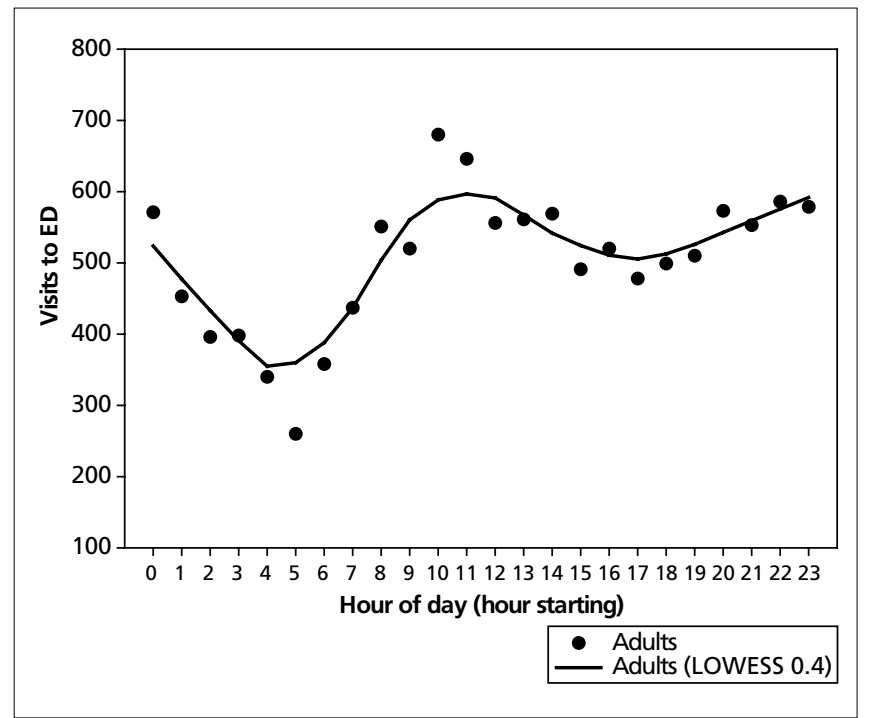

Fig. 4. Self-inflicted injury visits by hour of day, adults only, 1998 to 2001.
Similar to other research, ${ }^{13,15}$ this study found that the most common method used in self-inflicted injury (in Western societies) is self-poisoning. This study also confirms that males are more likely to use methods of self-inflicted injury with a higher degree of lethality than females.

Rates of repeat visits to the ED within 365 days of the index self-inflicted injury were particularly high. Mortality studies have shown that individuals who engage in selfharming behaviour are more likely to die of violence or injuries. ${ }^{8-11}$ In addition, a service-use study in Edmonton recently showed that individuals with self-inflicted injuries more commonly return to the ED for a variety of reasons than do other populations. ${ }^{25}$ The $18 \%$ rate of return visits for a self-inflicted injury within 365 days of the index selfinflicted injury reported in the present study corresponds well to an average rate of $16 \%$ reported elsewhere. ${ }^{12}$ Discharge rates were notably high in this study, even among patients who used deadly methods such as firearms, hanging, jumping or gas. However, no data were collected on referrals for post-discharge treatment, so it is not possible to comment on the comprehensiveness of care received or on any relation to rates of repeat visits. It does suggest that if interventions aimed at prevention were prescribed, the majority would have been applied in the outpatient setting.

Several studies have reported on temporal factors associated with self-inflicted injuries, with a particular focus on month of year. Some consistent trends have been reported in data by month; rates of self-inflicted injury are higher in late spring or early summer and lower from November to January, ${ }^{26-30}$ which agrees with results from the present

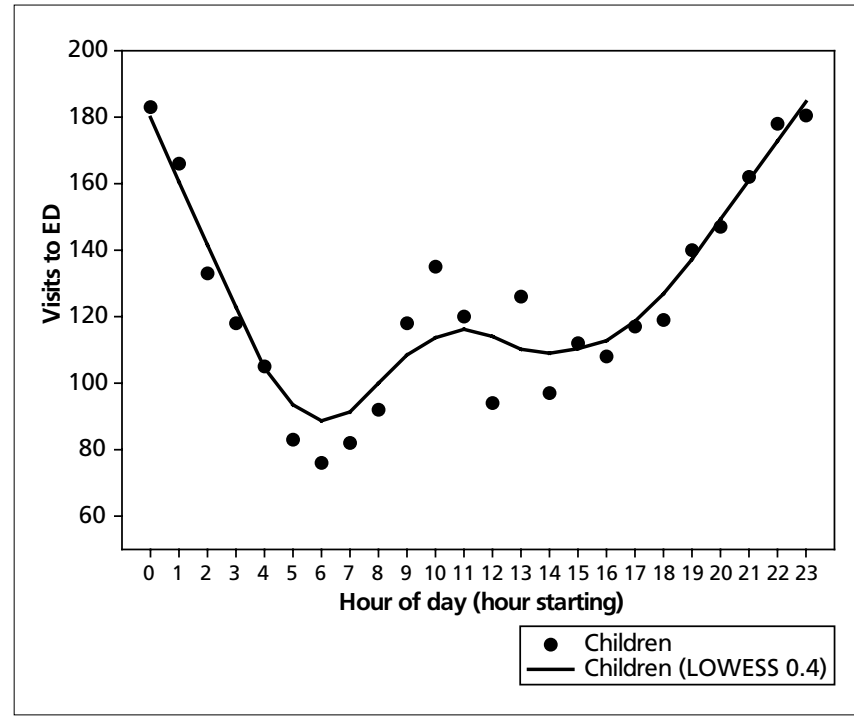

Fig. 5. Self-inflicted injury visits by hour of day, children only, 1998 to 2001. 
study. There is less evidence regarding day of week. The WHO/EURO study ${ }^{28}$ found considerable variation among 16 centres with regard to rates by day of week, and a study in Singapore found that rates were lowest on Saturday. ${ }^{27}$ The lack of agreement between sites, including data from the present study, suggests that societal and cultural factors may be responsible for some of the temporal variation with regard to day of week. Finally, the WHO/EURO study reported that rates were highest in most centres between $2000 \mathrm{~h}$ and midnight. ${ }^{26}$ No site reported a peak in late morning, which was found in the present study. Although the late morning peak was somewhat surprising, the trend was observed in all 3 years studied.

The collection of administrative data on health care provides enormous research opportunities, particularly for studying health events that may be difficult to measure in

\begin{tabular}{|c|c|c|c|}
\hline Subsidy level* & 1998/1999 & $1999 / 2000$ & $2000 / 2001$ \\
\hline No subsidy & 1119.8 & 116.0 & 121.4 \\
\hline $\begin{array}{l}\text { Full / Partial } \\
\text { subsidy }\end{array}$ & 197.4 & 210.0 & 211.6 \\
\hline Social services & 1296.0 & 1396.0 & 1398.6 \\
\hline Treaty status & 849.1 & 958.0 & 966.0 \\
\hline
\end{tabular}

Table 3. Self-inflicted injury visits by method used and gender, 1998 to 2001

\begin{tabular}{lcc} 
& \multicolumn{2}{c}{ Gender, no. (and \%) } \\
\cline { 2 - 3 } Method used & Female & Male \\
\hline Self-poisoning & $10745(81.4)$ & $6498(70.7)$ \\
Cutting or piercing & $1187(14.3)$ & $1315(14.3)$ \\
Firearms / Hanging / & & \\
$\quad$ Jumping / Gas & $256(1.9)$ & $622(6.8)$ \\
Other & $313(2.4)$ & $760(8.3)$ \\
\hline All methods & $9195(100.0)$ & $13201(100.0)$ \\
\hline
\end{tabular}

the general population, such as self-inflicted injuries. Possible analyses include investigations into associations between self-inflicted injuries and socio-demographic information, characteristics of treatment, trends over time, and utilization of services. However, these data can be biased if there are systematic differences in access of services by differing segments of the population. Fortunately, these biases can be eliminated if the entire population is necessarily covered by the data collection, as is the case with the Canadian health care system. Data systems such as the ACCS database used in this study provide a unique opportunity for large-scale epidemiological investigations of self-inflicted injuries in a non-biased fashion.

\section{Limitations}

A few limitations should be noted. First, this study only captured individuals with self-inflicted injuries who sought emergency medical treatment. The extent of self-inflicted injuries that do not receive medical treatment is unclear; however, it has been reported that as few as one-quarter of "suicide attempts" may receive medical attention. ${ }^{31}$ If so, the rates reported in the present study may be significantly under-estimating the true rate of self-inflicted injury. However, if the goal is to have complete coverage of the population, it is impractical to assess self-inflicted injuries in a manner other than to focus on those that are medically treated. ${ }^{18} \mathrm{~A}$ final limitation is that there may be visits for self-inflicted injuries that did not receive a code identifying it as a "Suicide or Self-inflicted injury" (ICD-9-CM E950-E959). It has been reported that suicide deaths often receive a cause of death of "Accidental" or "Undetermined." ${ }^{\prime 2,33}$ A recent Canadian study using clinician ratings of hospital charts showed that $39 \%$ of deliberate self-poisoning did not receive the appropriate code identifying it as deliberate. ${ }^{34}$ Similarly, a study in Oxford using data from 1980 to 1985 found that $80 \%$ of individuals with selfinflicted injuries did not receive an ICD-9-CM code identifying it correctly. ${ }^{35}$ However, data from California found

Table 4. Self-inflicted injury visits by method used and disposition status, 1998 to 2001

\begin{tabular}{lcccrc} 
& \multicolumn{5}{c}{ Disposition status, no. (and \%) } \\
\cline { 2 - 6 } Method used & Discharged & \multicolumn{1}{c}{ Left* } & Admitted & Transferred & Died \\
\hline Self-poisoning & $10705(62.1)$ & $292(1.7)$ & $5413(31.4)$ & $807(4.7)$ & $21(0.1)$ \\
Cutting or piercing & $2412(75.4)$ & $46(1.4)$ & $592(18.5)$ & $145(4.5)$ & $2(0.1)$ \\
$\begin{array}{l}\text { Firearms / Hanging / } \\
\quad \text { Jumping / Gas }\end{array}$ & $350(39.4)$ & $10(1.1)$ & $277(31.2)$ & $139(15.7)$ & $112(12.6)$ \\
Other & $822(78.7)$ & $11(1.1)$ & $181(17.3)$ & $22(2.1)$ & $9(0.9)$ \\
\hline All methods & $14289(63.9)$ & $359(1.6)$ & $6463(28.9)$ & $1113(5.0)$ & $144(0.6)$ \\
\hline *Left prior to being seen by a physician or left against medical advice. & & & \\
\hline
\end{tabular}


much higher rates of sensitivity (95\%) for correctly identifying self-inflicted injuries through ICD-9-CM codes. ${ }^{36}$ The extent of mis-coding in the ACCS database used for this study is unclear. Furthermore, it is difficult to ascertain whether mis-coding occurs because of error or because of social stigma associated with suicidal behaviour. Regardless, any mis-coding would tend to underestimate the true prevalence of self-inflicted injuries.

\section{Conclusions}

In conclusion, this study documents the magnitude and epidemiology of ED visits for self-inflicted injuries in a Canadian province using a unique population-based database. From these data, it would appear that self-inflicted injuries are a major ED and public health care issue with important socio-demographic, regional and temporal variation. These results should be helpful to direct further research and institute focussed interventions for prevention.

\section{Competing interests: None declared.}

Acknowledgements: Dr. Rosychuck is supported by the Alberta Heritage Foundation for Medical Research, Edmonton, Alta., as a Population Health Investigator. Mr. Colman was supported in part by the Canadian Association of Emergency Physicians Research Consortium, Ottawa, Ont. Dr. Rowe is supported by Canadian Institute of Health Research, Ottawa, Ont., as a Canada Research Chair.

Support for this project was generously provided by Alberta Health and Wellness and the Division of Emergency Medicine, University of Alberta, Edmonton, Alta.

This work was completed in collaboration with the ED Atlas Group. [See screened box below.]

ITOther members of the ED Atlas Group (not listed as authors) are: Drs. Brian R. Holroyd, Michael Bullard, Terry P. Klassen, David Johnson and William Craig, and Carol Spooner, BScN, MSc, and Don Voaklander, PhD.

\section{References}

1. Weissman MM, Bland RC, Canino GJ, Greenwald S, Hwu HG, Joyce PR, et al. Prevalence of suicide ideation and suicide attempts in nine countries. Psychol Med 1999;29(1):9-17.

2. International Classification of Diseases, 9th rev, 3rd ed. (Clinical Modification). Los Angeles: Practice Management Information Corporation; 1989.

3. Dyck RJ, Bland RC, Newman SC, Orn H. Suicide attempts and psychiatric disorders in Edmonton. Acta Psychiatr Scand Suppl 1988;338:64-71.

4. Thompson AH, Bland RC. Social dysfunction and mental illness in a community sample. Can J Psychiatry 1995;40(1):15-20.
5. Suominen K, Henriksson M, Suokas J, Isometsa E, Ostamo A, Lonnqvists J. Mental disorders and comorbidity in attempted suicide. Acta Psychiatr Scand 1996;94(4):234-40.

6. Goldney RD. A global view of suicidal behaviour. Emerg Med (Fremantle) 2002;14(1):24-34.

7. Colman I, Newman SC, Schopflocher D, Bland RC, Dyck RJ. A multivariate study of predictors of repeat parasuicide. Acta Psychiatr Scand 2004;109(4):306-12.

8. Hawton K, Fagg J. Suicide, and other causes of death, following attempted suicide. Br J Psychiatry 1988;152:359-66.

9. Harris EC, Barraclough B. Excess mortality of mental disorder. Br J Psychiatry 1998;173:11-53.

10. Hall DJ, O'Brien F, Stark C, Pelosi A, Smith H. Thirteen-year follow-up of deliberate self-harm, using linked data. Br J Psychiatry 1998;172:239-42.

11. Ostamo A, Lonnqvist J. Excess mortality of suicide attempters. Soc Psychiatry Psychiatr Epidemiol 2001;36(1):29-35.

12. Owens D, Horrocks J, House A. Fatal and non-fatal repetition of self-harm: systematic review. Br J Psychiatry 2002;181:193-9.

13. Schmidtke A, Bille-Brahe U, DeLeo D, Kerkhof A, Bjerke T, Crepet $\mathrm{P}$ et al. Attempted suicide in Europe: rates, trends and sociodemographic characteristics of suicide attempters during the period 1989-1992. Results of the WHO/EURO Multicentre Study on Parasuicide. Acta Psychiatr Scand 1996;93(5):327-38.

14. MoScicki EK, O’Carroll P, Rae DS, Locke BZ, Roy A, Regier DA. Suicide attempts in the Epidemiologic Catchment Area Study. Yale J Biol Med 1988;61(3):259-68.

15. Spicer RS, Miller TR. Suicide acts in 8 states: incidence and case fatality rates by demographics and method. Am J Public Health 2000;90(12):1885-91.

16. Indian and Northern Affairs Canada. Terminology. Available: www.ainc-inac.gc.ca/pr/info/tln_e.html (accessed 2003 July 25).

17. Cleveland WS, Devlin SJ. Locally weighted regression: an approach to regression analysis by local fitting. J Am Stat Assoc 1988;83:596-610.

18. Platt S, Bille-Brahe U, Kerkhof A, Schmidtke A, Bjerke T, Crepet P, et al. Parasuicide in Europe: the WHO/EURO Multicentre Study on Parasuicide. I. Introduction and preliminary analysis for 1989. Acta Psychiatr Scand 1992;85(2):97-104.

19. Welch SS. A review of the literature on the epidemiology of parasuicide in the general population. Psychiatr Serv 2001;52 (3):368-75.

20. Rhoades ER. The health status of American Indian and Alaska native males. Am J Public Health 2003;93(5):774-8.

21. Trovato F. Canadian Indian mortality during the 1980s. Soc Biol 2000;47(1-2):135-45. 
22. Mahoney MC, Michalek AM. Health status of American Indians/Alaska Natives: general patterns of mortality. Fam Med 1998;30(3):190-5.

23. Malchy B, Enns MW, Young TK, Cox BJ. Suicide among Manitoba's aboriginal people, 1988 to 1994. CMAJ 1997;156(8): $1133-8$

24. Royal Commission on Aboriginal Peoples. Choosing life: special report on suicide among Aboriginal people. Ottawa (ON): Royal Commission on Aboriginal Peoples; 1995.

25. Colman I, Dryden DM, Thompson AH, Chahal AM, Borden K, Rowe $\mathrm{BH}$, et al. Utilization of the emergency department after self-inflicted injury. Acad Emerg Med 2004;11(2):136-42.

26. Jessen G, Andersen K, Arensman E, Bille-Brahe U, Crepet P, DeLeo D, et al. Temporal fluctuations and seasonality in attempted suicide in Europe. Arch Suicide Res 1999;5(1):57-69.

27. Ho BK, Kua EH, Hong C. Temporal variation in parasuicide among Singaporean Chinese. Aust N Z J Psychiatry 1998;32(4): 500-3.

28. Preti A. The influence of seasonal change on suicidal behaviour in Italy. J Affect Disord 1997;44(2-3):123-30.

29. Barker A, Hawton K, Fagg J, Jennison C. Seasonal and weather factors in parasuicide. Br J Psychiatry 1994;165(3):375-80.
30. Masterton G. Monthly and seasonal variation in parasuicide: a sex difference. Br J Psychiatry 1991;158:155-7.

31. Meehan PJ, Lamb JA, Saltzman LE, O'Carroll PW. Attempted suicide among young adults: progress toward a meaningful estimate of prevalence. Am J Psychiatry 1992;149(1):41-4.

32. O'Donnell I, Farmer R. The limitations of official suicide statistics. Br J Psychiatry 1995;166(4):458-61.

33. Ohberg A, Lonnqvist J. Suicides hidden among undetermined deaths. Acta Psychiatr Scand 1998;98(3):214-8.

34. Rhodes AE, Links PS, Streiner DL, Dawe I, Cass D, Janes S. Do hospital E-codes consistently capture suicidal behaviour? Chronic Dis Can 2002;23(4):139-45.

35. Sellar C, Goldacre MJ, Hawton K. Reliability of routine hospital data on poisoning as measures of deliberate self poisoning in adolescents. J Epidemiol Community Health 1990;44(4):313-5.

36. Iribarren C, Sidney S, Jacobs DR Jr, Weisner C. Hospitalization for suicide attempt and completed suicide: epidemiological features in a managed care population. Soc Psychiatry Psychiatr Epidemiol 2000;35(7):288-96.

Correspondence to: Dr. Brian H. Rowe, Research Director, Division of Emergency Medicine, University of Alberta, 1G1.43 Walter Mackenzie Health Sciences Centre, 8440 - 112 St., Edmonton AB T6G 2B7; 780 407-6761, fax 780 407-3982, Brian.Rowe@ualberta.ca 